\title{
Densification Kinetics of Titanium Carbide- Based Cermet During the Pressure Sintering
}

\author{
Hrebenok TP, Subbotin VI and Kovalchenko MS* \\ IN Frantsevich Institute for Problems of Material Science, Ukraine
}

\section{Opinion}

Titanium carbide-based cermets with the addition of other carbides and with metal binders

ISSN: 2578-0255

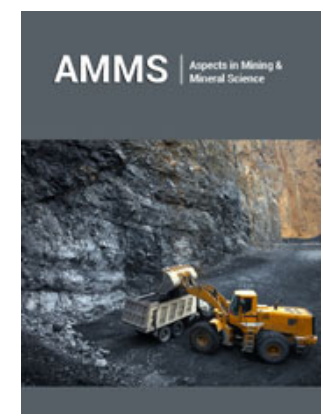

*Corresponding author: Kovalchenko M S, IN Frantsevich Institute for Problems of Material Science, NAS of Ukraine, Ukraine

Submission: 㘹 February 24, 2020

Published: 監February 27, 2020

Volume 4 - Issue 4

How to cite this article: Hrebenok TP, Subbotin VI, Kovalchenko MS*. Densification Kinetics of Titanium Carbide-Based Cermet During the Pressure Sintering. Aspects Min Miner Sci.4(4). AMMS.000591.2020.

DOI: 10.31031/AMMS.2020.04.000591

Copyright@ Kovalchenko M S, This article is distributed under the terms of the Creative Commons Attribution 4.0 International License, which permits unrestricted use and redistribution provided that the original author and source are credited. of nickel, iron and their alloys are used in mechanical engineering technology and instrumentmaking industry as wear-resistant and corrosion-resistant materials and coatings. The goal remains to increase the mechanical and functional properties of cermets, and for this research is being conducted aimed at optimizing the compositions and improving the technology for their manufacture. This report presents the results of a study of nonisothermal pressure sintering a powder mixture containing, in addition to titanium carbide TiC, mass fractions of carbides: $4 \% \mathrm{VC}, 6 \% \mathrm{Mo}_{2} \mathrm{C}, 6 \% \mathrm{NbC}$, and $20 \% \mathrm{NiCr}$. Pressure sintering of powder mixtures was carried out on an induction heating unit made on the basis of a hydraulic press and a thyristor converter in an atmosphere formed as a result of the interaction of a graphite die with air. After preliminary slow heating, a sintering regime was established with a controlled heating rate of $15 \mathrm{~K} / \mathrm{min}$ under a constant pressure of $20 \mathrm{MPa}$. The obtained experimental data on the current change in relative density and temperature in the process of cermet sintering showed a regular acceleration of its densification with increasing temperature.

The processing of the experimental data was performed within the framework of the theory of bulk viscous flow of the porous body using the developed computer programs. The exact data on the densification rate was determined by the approximation method of the compaction curve by Lagrange polynomials, the differentiation of which yielded a derivative, that is, the densification rate, at each experimental point of the specified curve. A typical dependence of the relative density and temperature on the sintering time of the sample is presented below in the (Figure 1). The studied cermet is considered as a composite formed by a matrix having a theoretical material density and corresponding to a maximum relative density of 1 and pores whose density is equal to 0 . Quantitative data on the relative density $\rho$ and the densification rate enable the calculation of the current change in root-mean-square stress tm and strain rate in the matrix forming a porous composite.

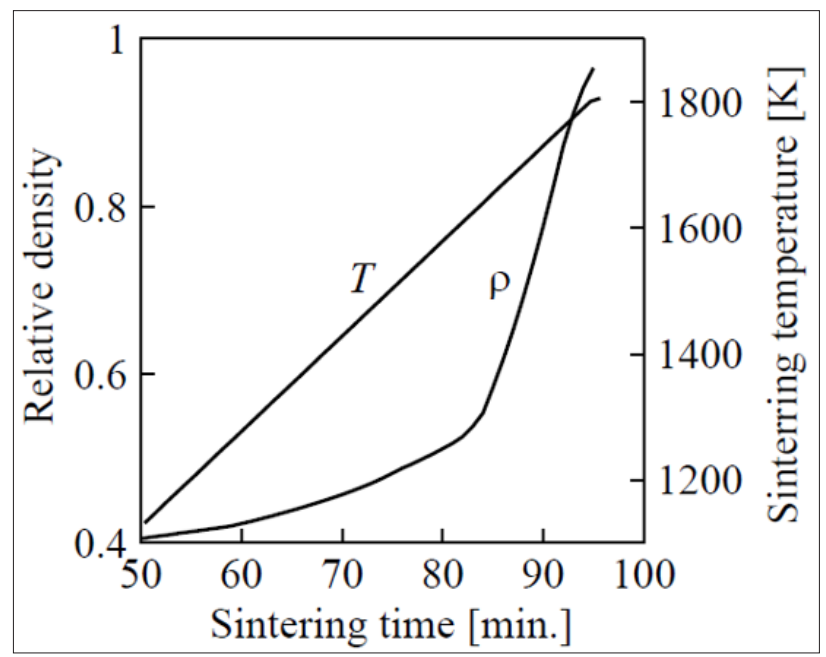

Figure 1: The cermet relative density $\rho$ and temperature $\mathrm{T}$ versus sintering time $\mathrm{t}$.

The quantities above are expressed by the formulae as follow: 


$$
\varepsilon_{m}^{\cdot}=\frac{1}{\rho} \frac{d \rho}{d t} \rho^{(2.5-2 \rho) /(2 \rho)} \sqrt{\frac{2-\rho^{2 / \rho}}{2\left(1-\rho^{2 / \rho}\right)}} \tau_{m}=\sigma_{1} \sqrt{\frac{2\left(1-\rho^{2 / \rho}\right)}{\rho 2.5 / \rho\left(2-\rho^{2 / \rho}\right)}}
$$

Here $\sigma_{1}$ is the axial pressure and $\mathrm{t}$ is time.

The results of the calculation are showed in Figure 2. The root-mean-square stresses gradually decreases during the cermet densification from the initial value of $327.6 \mathrm{MPa}$ at a temperature $825^{\circ} \mathrm{C}$ to $101.1 \mathrm{MPa}$ at $1298{ }^{\circ} \mathrm{C}$ and in the range of temperatures corresponding to sintering in the presence of the liquid phase, goes to zero. The root-mean-square rate gradually increases with the increase in temperature during the solid phase sintering from $4.42 \cdot 10^{-5} \mathrm{~s}^{-1}$ at $825{ }^{\circ} \mathrm{C}$ to $1.43 \cdot 10^{-4} \mathrm{~S}^{-1}$ at $1298{ }^{\circ} \mathrm{C}$. During the transition to the stage of liquid-phase sintering, an increase in the densification rate to $2.6 \cdot 10^{-4} \mathrm{~s}^{-1}$ at $1393{ }^{\circ} \mathrm{C}$ is replaced by a sharp decrease in it as the porous body densifies. The transition to the liquid-phase sintering stage is particularly clear on plots for logarithm of the relative density function rate [1] versus the reciprocal thermodynamic temperature (Figure 3), from which the activation energy of the matrix viscous flow was determined [1]. It is established that solid-phase pressure sintering is controlled by the mechanism of nonlinear creep (n»1.5) with activation energy, which depends on the stress in the material, and liquid-phase sintering mechanism by virtually linear creep $(n=1)$ with activation energy of $542 \mathrm{~kJ} / \mathrm{mol}$.

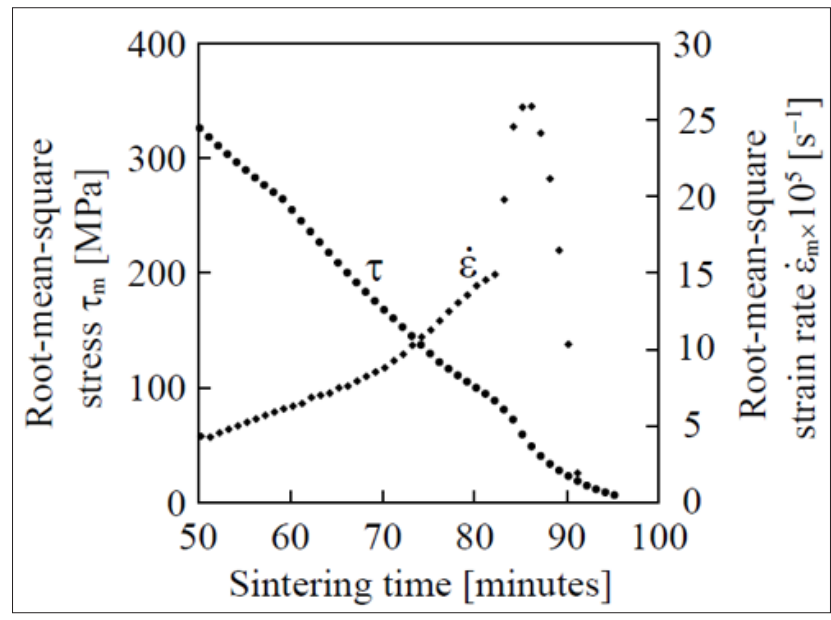

Figure 2: Root-mean-square stress tm and strain rate $\varepsilon_{m}$ in the matrix.

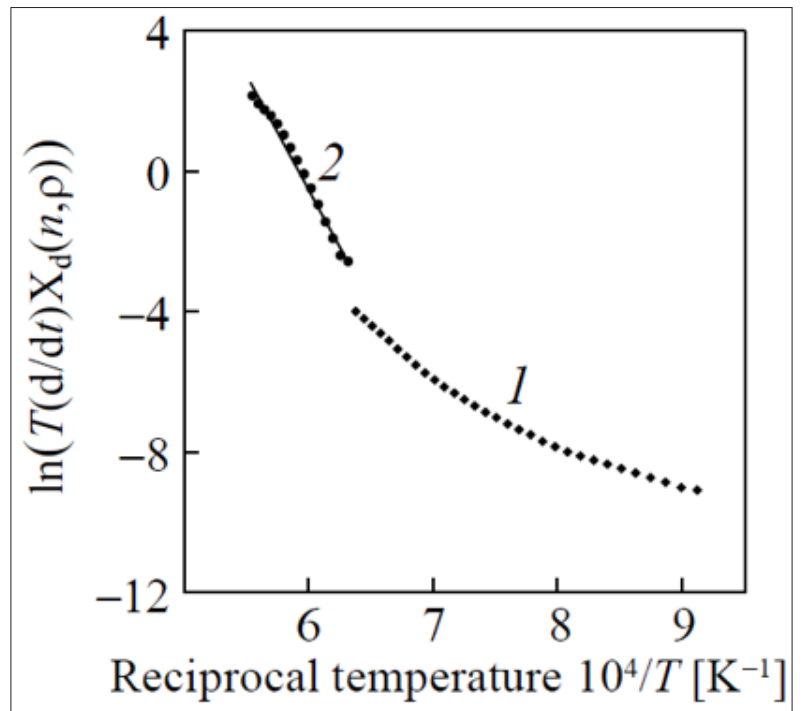

Figure 3: Logarithm of the relative density function rate $\ln (\mathrm{T}(\mathrm{d} / \mathrm{dt}) \mathrm{Xd}(\mathrm{n}, \rho))$ vs. reciprocal temperature $\mathrm{T}^{-1}$ for solid-phase (1) and liquid-phase (2) pressure sintering.

\section{References}

1. Kovalchenko MS (2016) Rheology and kinetics of pressure sintering. Materials Science Forum 835: 76-105.

For possible submissions Click below: 